\title{
Educação em Saúde mental em época de pandemia de COVID-19
}

\author{
Ana Tereza Crisóstomo da Silva Lins \\ Camila Emerenciano Berrondo Menezes de Andrade \\ Mariana Terra Alves de Oliveira \\ Raianne Cristina da Rocha Rodrigues \\ Monique Guerreiro de Moura \\ Luz Marina Alfonso Dutra \\ Escola Superior em Ciências da Saúde- ESCS
}

\begin{abstract}
RESUMO: O presente projeto foi elaborado no mês de maio de 2020 e teve como objetivo apresentar a confecção de um material educativo que tem como finalidade orientar os usuários da atenção básica do Distrito Federal a respeito das medidas de prevenção da COVID-19 e instruir a população sobre estratégias para manter a saúde mental em período de pandemia e quarentena domiciliar. Constitui-se como uma construção dialógica que foi elaborada virtualmente em forma de folder, sendo desenvolvida pelos residentes e preceptoras do Programa de Residência Multiprofissional em Saúde do Adulto e do Idoso - PRMSAI. Observase que o uso das tecnologias em saúde compreende, atualmente, uma ferramenta inovadora que vem apresentando crescente adesão pelos profissionais de saúde, como estratégia de educação popular, promoção da saúde e do autocuidado. Destarte, almeja-se que o referido material seja utilizado na versão digital ou impressa, como forma de disseminar a informação e orientar a população de modo geral que acessa os serviços de saúde.
\end{abstract}

Palavras-chave: COVID-19; Saúde Mental; Promoção da Saúde; Prevenção em Saúde; Educação em Saúde.

\section{Mental Health Education in a time of the COVID-19 pandemic}

\begin{abstract}
This project was developed in May of 2020 and aimed to present the preparation of an educational material that aims to guide users of primary care in the Federal District regarding the prevention measures of COVID-19 and instruct the population on strategies to maintain mental health in times of pandemic and home quarantine. It is constituted as a dialogical construction in which it was elaborated virtually in the form of a folder, being developed by residents and tutors of the Multiprofessional Residency Program in Adult and Elderly Health - PRMSAI. It is observed that the use of health technologies currently comprises an innovative tool that has been showing increasing adhesion by health professionals, as a popular education strategy, health promotion and self-care. Thus, it is hoped that the referred material will be used in digital or printed version, as a way of disseminating information and guiding the population in a general way that access health services.
\end{abstract}

Keywords: COVID-19; Mental Health; Health Promotion; Health Prevention; Health Education. 


\section{INTRODUÇÃO}

O coronavírus corresponde a uma família de vírus que causa infecções respiratórias, incluindo o novo coronavírus (SARS-CoV-2), este último foi descoberto recentemente em dezembro de 2019 na cidade chinesa de Wuhan $^{1}$. O grupo dos coronavírus constitui uma classe de vírus que apresenta RNA de cadeia positiva e que contém quatro gêneros: alfa-, beta-, gamae delta coronavírus ${ }^{1}$. O termo coronavírus remete ao aspecto microscópico deste vírus, que se assemelha a picos no formato de coroa em sua superfície ${ }^{2}$.

Embora o SARS-CoV-2 tenha sido amplamente discutido recentemente, os primeiros registros de infecções decorrentes de coronavírus na espécie humana foram relatados pela primeira vez em $1937^{3}$ A infeção pelo novo coronavírus consiste atualmente em um dos maiores problemas de saúde pública mundialmente ${ }^{4-5}$. De acordo com a Organização Mundial de Saúde (OMS), cerca de $80 \%$ dos pacientes diagnosticados com a Coronavirus disease 19 (COVID-19) não apresentam sintomas, porém, 20\% destes casos podem precisar de atendimento hospitalar e outros $5 \%$ podem necessitar de suporte ventilatório para ajudar no tratamento da insuficiência respiratória ${ }^{6}$.

Este tipo de infecção apresenta um quadro clínico que afeta principalmente o sistema respiratório. Trata-se, portanto, de uma infecção que pode evoluir com ausência de sinais e sintomas, ou com sintomas leves ou pode desenvolver também quadros respiratórios graves, que variam entre: tosse, febre alta, coriza, dor de garganta e insuficiência respiratória ${ }^{7}$

Como profissionais de saúde, torna-se imprescindível que as equipes interprofissionais de saúde e a população de modo geral estejam bem orientadas acerca dos aspectos biológicos e interferência deste novo vírus nas questões biopsicossociais de ambos os grupos, visando contribuir de forma promissora para o esclarecimento da população e adoção das melhores medidas de prevenção e controle da saúde, no intuito de minimizar ao máximo possível os riscos de transmissão e como forma de estabelecer medidas de promoção da saúde e proteção 
da saúde mental dos indivíduos, contribuindo assim para redução de danos diante do impacto do isolamento na saúde mental da população.

\section{OBJETIVO GERAL}

Apresentar a confecção de uma tecnologia educativa que tem como finalidade orientar os usuários da atenção básica a respeito das medidas de prevenção da COVID-19, apontando as estratégias recomendadas para a manutenção da saúde mental em período de quarentena domiciliar.

\section{MÉTODOS}

Constituiu-se como uma construção dialógica que foi elaborada virtualmente em forma de folder, tendo sido desenvolvida pelos residentes e preceptoras do Programa de Residência Multiprofissional em Saúde do Adulto e do Idoso - PRMSAI vinculado à Secretaria de Saúde do Distrito Federal - SES/DF. A referida confecção foi elaborada nos meses de abril e maio de 2020.

O desenvolvimento metodológico ocorreu em duas fases: a primeira através da realização de pesquisa do referencial teórico sobre o tema elencado, para nortear as informações que compuseram a construção dialógica supracitada. A segunda fase consistiu na elaboração do designer e layout em formato de folder na versão digital contendo informações direcionadas à população em geral da atenção básica de forma clara e objetiva sobre o que é a COVID-19, as principais formas de prevenção e estratégias para manter a saúde mental da população em época de pandemia.

Para a operacionalização da montagem gráfica foi utilizado o programa Canva, disponibilizado nas plataformas digitais de forma gratuita. $\mathrm{O}$ modelo utilizado foi em formato de folheto, que posteriormente poderá ser impresso e disponibilizado de forma física à população. Para garantir uma leitura legível, foram utilizadas as fontes no corpo do texto- 
Arimo no tamanho 12 e no título foi utilizada a fonte Lato com tamanho 14. No título principal contido na primeira página foi empregada a fonte Latoem tamanho 30. Como estratégia de despertar a curiosidade do leitor, foram utilizadas cores contrastantes e fundo em branco, lilás e azul turquesa.

A população alvo corresponde aos usuários das diversas faixas etárias e ambos os sexos, que frequentam o serviço de atenção básica do Distrito Federal.

A definição da temática teve como base a crescente necessidade no aumento de buscas relacionadas a informações sobre o novo coronavírus, especificamente o SARS-CoV-2.

As respectivas demandas foram elencadas por estarem relacionadas à atual conjuntura mundial diante de uma nova ameaça à saúde global da população. O conteúdo textual foi elaborado com o objetivo de ser rico em informações, porém de forma clara e resumida, trazendo informações com conteúdo científico, porém de forma elucidativa como meio de chamar atenção da população e torná-lo de fácil compreensão, haja vista que, a maioria dos materiais educativos em saúde é elaborado com conteúdo extenso, promovendo assim, uma leitura cansativa e de difícil interpretação pela população.

Ressalta-se que, durante a elaboração deste produto informativo, houve a constante preocupação com a adequação da linguagem e das ilustrações nele contidos, de modo a facilitar a compreensão por parte dos usuários, evitando-se desse modo, a utilização de termos técnicos de saúde.

\section{RESULTADOS}

A respectiva construção dialógica apresenta o seguinte título: “COVID-19 E SAÚDE MENTAL". O material foi elaborado em formato de folder possuindo frente e verso que segue a seguinte ordem lógica das informações: a versão frontal contém a capa com a disposição do título do folder, seguido da explicação dos seguintes questionamentos: “O que é a COVID-19?" Que dispõe brevemente do que se trata a doença. 
Posteriormente tem-se o esclarecimento de "Quais os sintomas mais comuns?" e "Com quanto tempo aparecem os sintomas?", seguido do esclarecimento de dúvidas a respeito das formas de prevenção da doença através do questionamento - "Como se prevenir?", o último questionamento contido nesta porção frontal do folder aborda a questão "Como cuidar da sua saúde mental durante a pandemia?", o qual discorre de forma breve sobre as principais medidas a serem adotadas no intuito de contribuir para a melhora da saúde mental dos indivíduos neste período de pandemia, como consta na figura 1.

FIGURA 1: Apresentação frontal do material educativo sobre COVID-19 e saúde mental.

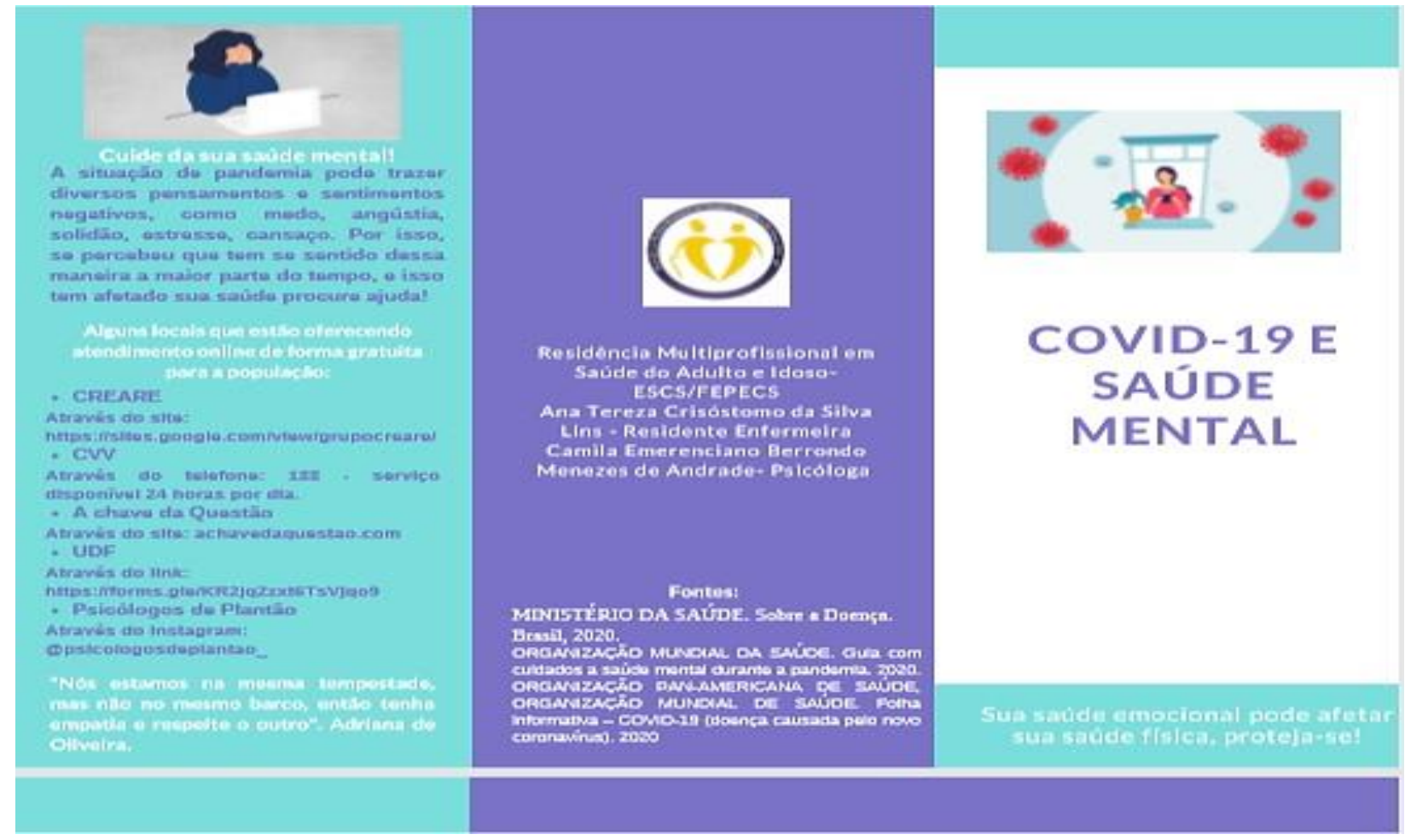

Fonte: OMS, SES-DF. 2020.

O verso do material apresenta alguns serviços de apoio psicológico em forma de atendimento online gratuito destinados à população, disponibilizando o link para acesso aos mesmos. Os serviços elencados foram: CREARE; CVV; A chave da Questão; UDF, como disposto na figura 2. 
FIGURA 2: Apresentação posterior (verso) do material educativo sobre COVID-19 e

saúde mental

\begin{tabular}{|c|c|c|}
\hline 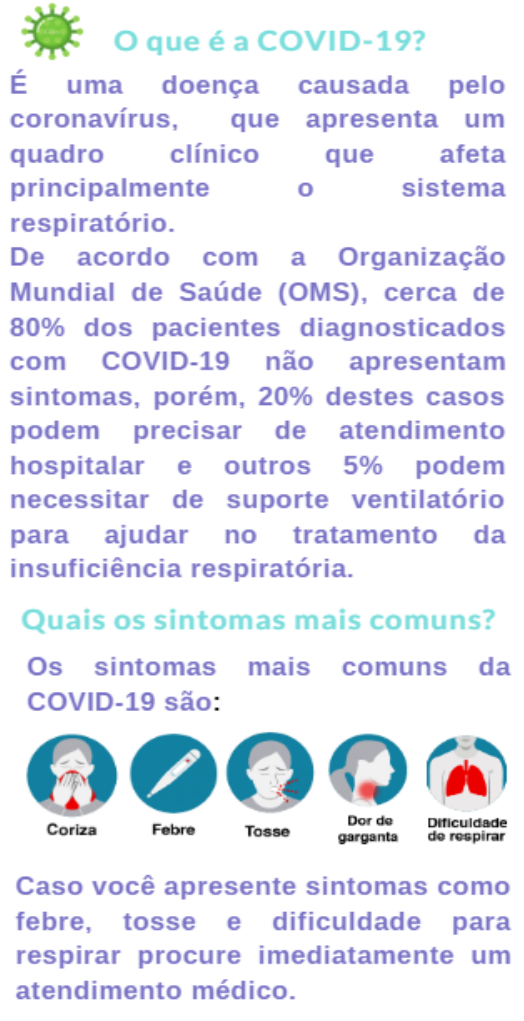 & 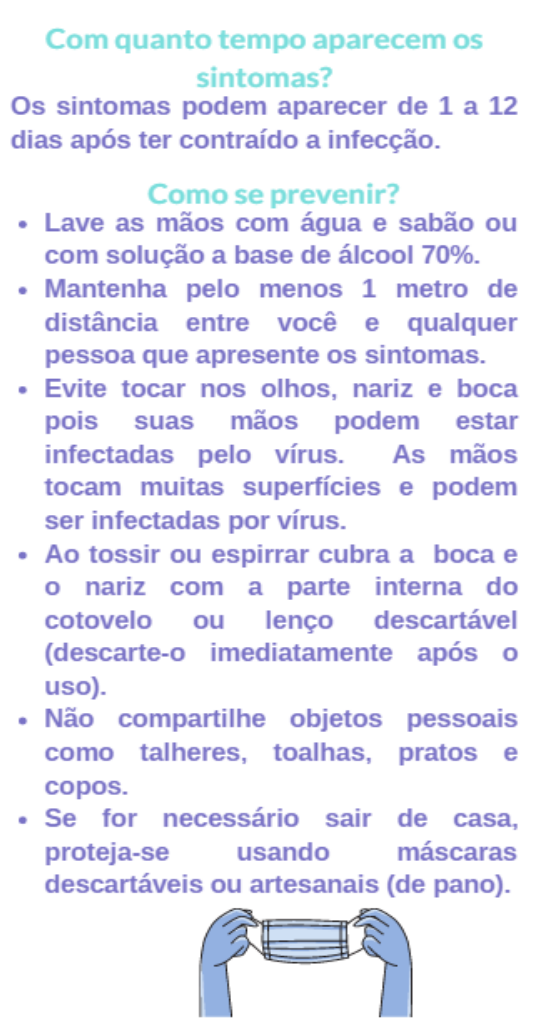 & $\begin{array}{l}\text { - É importante se informar, mas } \\
\text { escolha informações de fontes } \\
\text { confiáveis. } \\
\text { - Separe um horário do seu dia para } \\
\text { buscar essas informações, estar } \\
\text { constantemente em contato com } \\
\text { isso pode gerar pânico! } \\
\text { - Não replique informações não } \\
\text { confiáveis. } \\
\text { - Tente realizar atividades físicas. } \\
\text { - Realize atividades que lhe ofereça } \\
\text { satisfação. } \\
\text { - Se você tem alguma religião ou } \\
\text { espiritualidade tente praticá-la em } \\
\text { casa. } \\
\text { Ter ansiedade é normal, nos coloca } \\
\text { em estado de alerta, o problema é } \\
\text { quando isso ocorre de maneira } \\
\text { exacerbada e afeta negativamente } \\
\text { sua vida. } \\
\text { - Utilize a tecnologia a seu favor para } \\
\text { manter contato social com pessoas } \\
\text { significativas, não se isole! } \\
\text { - Precisamos nós respeitar nesse } \\
\text { momento. É esperado que haja } \\
\text { algumas oscilações de humor. }\end{array}$ \\
\hline
\end{tabular}

Fonte: OMS, SES/DF. 2020.

\section{DISCUSSÃO}

$\mathrm{Na}$ atual conjuntura, as tecnologias educativas são relevantes, pois, apresentam potencial de empoderamento social ao passo que permite ao ser humano adquirir conhecimento sobre a realidade em que está inserido, tornando-o capaz de compreender como as suas próprias ações podem influenciar direta ou indiretamente no seu processo saúde- doença, contribuindo assim, para mudanças no comportamento e ambiente em que se encontra ${ }^{8}$.

O emprego desse tipo de tecnologia por uma equipe interprofissional é imprescindível para a prestação de uma assistência de qualidade, contribuindo de forma positiva para a 
melhoria destas ações de saúde, haja vista que aborda diferentes conhecimentos especializados na temática contida no material elaborado ${ }^{8}$.

Diante de qualquer crise grave além de prestar esclarecimentos acerca da realidade enfrentada, surge a preocupação também com a saúde mental da população envolvida. Então, diversos pesquisadores e organizações têm investigado e compartilhado maneiras de intervenção psicológica e estudos teóricos para pautar a atuação ética dos psicólogos em todo o mundo. Um desses materiais é o Guia com cuidados à saúde mental durante a pandemia, que apresenta recomendações sobre cuidados com a saúde mental de diversas populações, como os indivíduos em geral, pessoas em grupo de risco e crianças 9 .

É esperado que a pandemia de COVID-19 ocasione, em alguma parte da população, perturbações psicológicas e sociais que afetem a capacidade de enfrentamento de toda a sociedade, em variados níveis de intensidade e propagação ${ }^{10}$.

São diversos os fatores que influenciam na saúde mental dos indivíduos durante uma pandemia, por exemplo, o método de controle mais efetivo da doença, que é o distanciamento social, impacta consideravelmente a população ${ }^{11}$. Por isso a necessidade de se pensar em estratégias como o uso de tecnologias para diminuir os efeitos que isso pode causar.

Outro fato que pode impactar no aspecto psicológico da população é a exposição exacerbada a informações, o que se agrava quando as informações são falsas. Por isso, é recomendado reduzir a ambiguidade e alta exposição às informações, especialmente as que podem gerar sintomas relacionados à ansiedade e estresse ${ }^{12}$. Por isso é tão importante garantir, à população, assistência apropriada em saúde mental, com recomendações práticas do que realizar e quais serviços procurar quando necessário.

Pode ocorrer também ansiedade em relação à própria saúde e acabar provocando uma interpretação errada das sensações corporais, fazendo com que os indivíduos confundam com 
sinais da doença e acabem se expondo e usando desnecessariamente serviços de saúde e sobrecarregando o referido sistema ${ }^{13}$.

Além disso, podem surgir sintomas, de leve a severos, de ansiedade, depressão, estresse, insônia, medo de contrair a doença ou de que algum familiar se infecte ${ }^{14}$. Por isso a necessidade de observar qualquer um dos sinais que indique que algum transtorno psicológico esteja em curso ocasionado pela pandemia.

\section{CONSIDERAÇÕES FINAIS}

Este instrumento foi elaborado por uma equipe interdisciplinar e será aplicado prontamente na prática clínica como um guia de apoio à população. Como foi realizado em base às necessidades relatadas pelos indivíduos nas consultas psicológicas por intermédio do tele atendimento, será digitalizado e enviado para os usuários com posterior feedback para avaliação. Há necessidade de estimular o uso de tecnologias de baixo custo que ofereçam suporte na área de saúde mental nos momentos de isolamento social que influenciam de forma negativa na qualidade de vida da população.

Torna-se de extrema importância ações como essas que busquem cuidar da saúde psicológica da população durante eventos de crise, como a pandemia de COVID-19. Ações como essas podem auxiliar na prevenção de agravos de saúde mental como depressão e ansiedade, o que se torna um incentivo para organizar mais estratégias como essa.

\section{REFERÊNCIAS BIBLIOGRÁFICAS}

1. Corman VM, Muth D, Niemeyer D, Drosten C. Hosts and sources of endemic human coronaviruses. Adv Virus Res. 2018; 100:163-88. ht tps://doi.org/10.1016/bs.aivir.2018.01.001

2. Abbag HF, El-Mekki AA, Al Bshabshe AA, Mahfouz AA, Al-Dosry AA, Mirdad RT, et al. Knowledge and attitude towards the Middle East respiratory syndrome coronavirus among health care personnel in the southern region of Saudi Arabia. J Infect Public Health. 2018 Sep - Oct;11(5):720 -2. https://doi.org/10.1016/j.jiph.2018.02.001 
3. Wolff MH, Sattar SA, Adegbunrin O, Tetro J. Environmental survival and microbicide inactivation of coronaviruses. In: Schmidt A, Wolff MH, Weber O. Coronaviruses with special emphasis on first insights concerning SARS. Base: Birkhäuser; 2005. p. 201-12.

4. Doremalen N, Bushmaker T, Morris DH, Holbrook MG, Gamble A, Williamson BN, et al. Aerosol and surfacestability of SARS-CoV-2 as compared with SARS-CoV-1. N Engl J Med. 2020 Mar; NEJMc2004973. https://doi.org/10.1056/NEJMc20049737.

5. Sabino-Silva R, Jardim AC, Siqueira WL. Coronavirus COVID-19 impacts to dentistry and potential salivary diagnosis. Clin Oral Investig. 2020 Apr;24(4):1619-21. https://doi.org/10.1007/s00784-020-03248-x.

6. Organização Mundial De Saúde - OMS. Folha informativa - COVID-19 (doença causada pelo Novo coronavirus). 2020.2 Disponível em: https://www.paho.org/bra/index.php?option=com_content\&view=article\&id=6101:covid19\&I temid=875. Acesso em: 29/04/2020.

7. Brasil. Ministério Da Saúde. Sobre a Doença. Brasil, 2020. Disponível em: https://coronavirus.saude.gov.br/sobre-a-doenca\#o-que-e-covid. Acesso em: 29/04/2020.

8. Texeira E (org.). Desenvolvimento de tecnologías cuidativo-educacionais. Porto Alegre: Moriá; 2017.

9. Organização Mundial de Saúde (OMS). Guia com cuidados a saúde mental durante a pandemia; 2020.

10. Ministério da Saúde (MS). Plano de contingência nacional para infecção humana pelo novo Coronavírus 2019-nCoV: Centro de operações de emergências em saúde pública (COE-nCoV), 2020.

11. Brooks SK, Webster RK, Smith LE, Woodland L, Wessely S, Greenberg N, Rubin GJ. The psychological impact of quarantine and how to reduce it: Rapid review of the evidence. The Lancet 2020; 395(10227): 912-920.

12. Faro A, Bahiano MA, Nakano TC, Reis C, Silva BFP, Vitti LS. COVID-19 e Saúde Mental: A emergência do cuidado. Scielo 2020; [acessado 2020 Mai 1] 1(1): 1-29. Disponível em: https://preprints.scielo.org/index.php/scielo/preprint/view/146/175

13. Asmundson GJG, Taylor S. Coronaphobia: Fear and the 2019-nCoV outbreak. Journal of Anxiety Disorders 2020; 70 (10): 1-24.

14. Schmidt B, Crepaldi MA, Bolze DAS, Silva LN, Demenech LM. Impactos na Saúde Mental e Intervenções Psicológicas Diante da Pandemia do Novo Coronavírus (COVID-19). Scielo 2020; [acessado 2020 Mai 1] 1(1): 1-26. Disponível em: https://preprints.scielo.org/index.php/scielo/preprint/view/58/version/62. 